\title{
PRODUTOS DE PANIFICAÇÃO COM CONTEÚDO CALÓRICO REDUZIDO
}

\author{
VERA DE TOLEDO BENASSI * \\ EDSON WATANABE * \\ ALEXANDRE RODRIGUES LOBO **
}

\begin{abstract}
Trata-se de revisão de literatura sobre os tipos de ingredientes desenvolvidos e/ou recomendados para serem utilizados em formulações de produtos de panificação com conteúdo calórico reduzido. Foram identificadas diversas possibilidades de redução do conteúdo calórico de produtos de panificação, cujos ingredientes devem ser testados e combinados, visando a obtenção de produtos que atendam às demandas do consumidor e às exigências da legislação em vigor.
\end{abstract}

PALAVRAS-CHAVE: PANIFICAÇÃO; SUBSTITUTOS DE GORDURA; SUBSTITUTOS DE AÇÚCAR; PRODUTOS "LIGHT".

\section{INTRODUÇÃO}

Nos últimos anos, o setor de panificação no Brasil tem realizado esforços para acompanhar as tendências de consumo observadas mundialmente que exigem produtos de maior conveniência e vida-de-prateleira mais longa.

A demanda por produtos com conteúdo calórico reduzido não decorre apenas do interesse do consumidor por produtos relacionados a dietas de controle de peso, mas da crescente preocupação com os benefícios trazidos pelos mesmos para a saúde. Esta preocupação se deve, principalmente, à grande controvérsia sobre as implicações nutricionais do consumo de gorduras e pelos benefícios do aumento do consumo de fibra na dieta (21).

* Pesquisadores, Embrapa Agroindústria de Alimentos, Rio de Janeiro, RJ.

(e-mail: edswat@ctaa.embrapa.br).

** Estagiário, Embrapa Agroindústria de Alimentos, Rio de Janeiro, RJ. 
Alimento nutritivo, o pão é apreciado pela maioria das pessoas de todas as faixas etárias e classes sociais. No entanto, parte da população vem evitando seu consumo e de outros produtos de panificação, mais ricos em açúcar e gordura como os bolos e biscoitos que representam problema para estes consumidores.

Vários produtos de panificação existentes no mercado brasileiro, sob a denominação "light", "diet" ou termos equivalentes, apresentam inconformidades com a legislação do país. No caso do pão de fôrma, além da praticidade, o crescimento do consumo está relacionado com a comercialização de diversos tipos, incluindo aqueles que atendem ao mercado de produtos com conteúdo calórico reduzido. Estes, às vezes, apresentam diferença desprezível no conteúdo calórico (2\%) quando comparados aos convencionais. Além do uso indevido da terminologia, observa-se que o pão "light" de determinada marca apresenta conteúdo calórico superior à versão convencional do mesmo pão de outra marca. Tal fato evidencia ausência de padronização entre os diferentes fabricantes deste tipo de produto. Durante muito tempo, as definições destes termos e as regulamentações sobre o assunto não foram suficientemente claras, gerando polêmicas e dúvidas para fabricantes e consumidores. No entanto, a Portaria n. 27 do Ministério da Saúde, de 13/01/98, esclareceu estas questões e estabeleceu regulamento técnico para a informação nutricional complementar (10). Já a Portaria n. 29, publicada no mesmo dia, dispôs sobre os padrões de identidade e qualidade dos alimentos para fins especiais, ou seja, aqueles adequados à utilização em dietas diferenciadas, visando atender às necessidades de pessoas com condições metabólicas e fisiológicas específicas (11). Segundo estas Portarias, o termo "light" ou "lite" só poderá ser utilizado para designar alimentos que apresentem baixo valor energético: máximo de $40 \mathrm{kcal} /$ $100 \mathrm{~g}$ para produtos sólidos e de $20 \mathrm{kcal} / 100 \mathrm{~g}$ para produtos líquidos. Quando se trata de alimento com valor energético reduzido em comparação ao convencional, a redução exigida é de pelo menos $25 \%$, com diferença maior que $40 \mathrm{kcal} / 100 \mathrm{~g}$ para sólidos ou $20 \mathrm{kcal} / 100 \mathrm{~g}$ para líquidos. $\mathrm{O}$ termo "diet" pode ser usado na designação de alimentos utilizados para controle de peso e para dietas com restrição de nutrientes ou ingestão controlada de açúcares.

Objetivou-se com esta revisão a coleta de informações, dispersas pela literatura, a respeito dos diferentes tipos de ingredientes desenvolvidos e/ ou recomendados para serem utilizados em formulações de produtos de panificação com conteúdo calórico reduzido. 


\section{PRODUTOS DE PANIFICAÇÃO “LIGHT”}

Os produtos de panificação, pelas características de sua composição, não podem ser designados como de baixo valor calórico. De modo geral, são ricos em carboidratos (o amido presente na farinha de trigo, outras féculas ou amidos, açúcares - sacarose, mel, xarope de glucose, etc.), em lipídios (óleos, gorduras, ovos, leite integral) e em proteínas (glúten da farinha, proteínas do leite, queijos e ovos), apresentando, com exceção dos produtos integrais, pequena quantidade de fibras.

Em termos de digestão, os carboidratos e as proteínas geram a mesma quantidade de energia (4 kcal/g). Já os lipídios geram quantidade superior $(9 \mathrm{kcal} / \mathrm{g})$ e as fibras não são digeridas pelo trato gastrointestinal humano, passando diretamente para as fezes. Para reduzir o valor calórico de determinado produto é necessário aumentar a quantidade de ingredientes que forneçam pouca ou nenhuma energia, diminuindo proporcionalmente a quantidade de ingredientes mais energéticos. Embora pareça simples, não é fácil modificar a formulação dos produtos de panificação que são tecnicamente complexos, pois ingredientes como gordura e açúcar lhes conferem importantes características de textura, maciez, sabor e conservação. O desenvolvimento de formulações para panificação com redução do valor calórico é, portanto, um desafio tecnológico. A lista de problemas comuns aos produtos com baixo teor de gordura ou de açúcar é extensa: perda de viscosidade e corpo, aeração e estrutura de células deficientes, redução da maciez e da umidade, baixa transferência de calor, dificuldade em atingir cor durante o assamento, diminuição da vida-deprateleira e deficiência na liberação de aromas (40).

No caso dos pães, a forma mais tradicional de se obter redução calórica é acrescentar fibras, geralmente farelos de cereais, os quais nem sempre apresentam condições higiênicas e toxicológicas satisfatórias para consumo humano. Embora o aumento no teor de fibras seja importante para combater problemas como a constipação intestinal e mesmo o câncer, a redução calórica não é significativa. Verifica-se também que é comum a utilização de glúten, principalmente para contrabalançar efeitos do farelo, já que este tende a diminuir o volume do pão e a torná-lo mais denso. A adição de glúten certamente representa benefício de ordem nutricional, tornando o alimento mais protéico, porém não propicia a redução de calorias. Portanto, os produtos com glúten (pão, macarrão) são adequados para quem necessita ingerir menos carboidratos, como os diabéticos, mas não para as pessoas em dieta para redução de peso. Desta forma, o pão de glúten não é necessariamente "light", embora o consumidor 
freqüentemente assim o considere. Este tipo de situação também ocorre com produtos doces, nos quais é comum a substituição do açúcar por edulcorantes, o que reduz parcialmente o conteúdo calórico e torna o produto mais adequado ao consumo por diabéticos. Porém, em se tratando de produtos como o bolo, por exemplo, a retirada do açúcar pode não ser suficiente para caracterizá-lo como "light", uma vez que o produto continua contendo ingredientes altamente calóricos como ovos, margarina, leite, etc.

Para a obtenção de produtos de panificação com conteúdo calórico reduzido é preciso introduzir modificações na formulação, de maneira a substituir alguns dos ingredientes por outros que exerçam funções tecnológicas semelhantes e contribuam com aporte calórico menor. Os produtos resultantes devem apresentar características semelhantes aos convencionais, inclusive (e principalmente) o sabor (43). Os consumidores estão ficando cada vez mais exigentes e não mais se satisfazem com produtos que não lhes faça mal e cujo gosto, textura ou aparência lembrem apenas remotamente o similar convencional. Para alcançar bons resultados é preciso lançar mão de ingredientes novos, desenvolvidos especificamente com esta finalidade, os quais ainda não são amplamente conhecidos por todo o setor industrial.

\section{SUBSTITUTOS DO AÇÚCAR}

A substância normalmente chamada de "açúcar" é a sacarose, o mais utilizado dos açúcares. Além de seu poder adoçante e sabor agradável, a sacarose contribui para a aparência, a textura, o sabor e a estabilidade dos produtos. Constitui substrato para as leveduras na fermentação, atua nas reações de escurecimento não-enzimático, diminui o ponto de congelamento, atua como agente de corpo e como conservante. A ingestão de açúcar não apresenta relação direta com a obesidade, embora contribua para o fornecimento excessivo de energia, responsável pela obesidade. Na verdade, apenas a cárie dentária tem como causa específica a ingestão de sacarose, pois não há nem mesmo evidências de que seu uso cause diabetes (13).

Além da sacarose, outros açúcares são utilizados em alimentos, principalmente:

a frutose, que pode ser consumida por diabéticos, é cariogênica. Pode reduzir o aporte calórico, pois sendo o mais doce de todos os 
açúcares naturais permite que seja consumida em menor quantidade; - a glicose apresenta perfil de doçura intermediário entre o da sacarose e o da frutose. É cariogênica e não pode ser consumida por diabéticos; - a lactose, açúcar predominante no leite, apresenta doçura cerca de 5 vezes menor que a sacarose, sendo o açúcar de menor doçura. Sua utilização deve ser restrita aos casos de indivíduos que apresentam intolerância específica (deficiência enzimática); e

- o xarope de milho (glicose), obtido por hidrólise ácida ou enzimática do amido, é absorvido mais lentamente, causando menor elevação da glicose sangüínea e menor tendência à formação de placa bacteriana.

Outras substâncias, naturais ou sintéticas, conhecidas como edulcorantes, apresentam ação adoçante, podendo substituir a sacarose. Alguns destes compostos são conhecidos como edulcorantes intensos, pois fornecem doçura acentuada, sendo utilizados em quantidades muito pequenas. Geralmente são não-nutritivos ou pouco calóricos e não apresentam ação cariogênica. Entre os edulcorantes não-nutritivos, ou seja, aqueles que não são metabolizados pelo organismo, não fornecendo energia, encontram-se $(7,13)$ :

- a sacarina, cuja doçura é cerca de 300 vezes a da sacarose, revela freqüentemente residual amargo;

- o ciclamato, de 30 a 50 vezes mais doce que a sacarose, apresenta sabor residual doce-azedo desagradável;

- o acesulfame-K, cerca de 180 a 200 vezes mais doce do que a sacarose, apresenta perfil de doçura semelhante ao da glicose;

- a sucralose, obtida a partir do açúcar comum, cuja doçura pode variar de 400 a 800 vezes em relação à sacarose (5).

Os edulcorantes nutritivos fornecem quantidades variadas de energia, porém contribuem para a redução do valor energético dos alimentos, como é o caso do aspartame. Este composto é derivado de dois aminoácidos, a fenilalanina e o ácido aspártico. Embora seu valor calórico seja igual ao da sacarose $(4 \mathrm{kcal} / \mathrm{g})$ é utilizado em quantidades mínimas, devido à sua intensa doçura (cerca de 180 vezes a da sacarose), o que proporciona diminuição no teor calórico. Pode ser consumido por diabéticos, mas não por portadores de fenilcetonúria, doença genética que altera o metabolismo da fenilalanina $(7,13)$.

Existem também edulcorantes derivados de extratos de vegetais, como: 
- esteviosídeo, extraído da Stevia reubaudiana, apresenta perfil de doçura semelhante ao da sacarose, contudo mostra sabor residual amargo de mentol, quando em altas concentrações. Não é calórico nem cariogênico e pode ser consumido por diabéticos;

- inulina, principal carboidrato de reserva de algumas plantas como alcachofra de Jerusalém, chicória e dália, pode ser utilizada como matéria-prima para produção de frutose ou xaropes com alto teor de frutose. Apresenta valor calórico de $1 \mathrm{kcal} / \mathrm{g}$ e pode ser consumida por diabéticos (13).

A ausência de açúcar em produtos processados, que normalmente o contém em quantidades elevadas, altera a retenção de umidade e diversas características como sabor, textura, cor e aroma, dificultando a obtenção de produto similar ao convencional. É necessário utilizar ingredientes que apresentem função de agentes de corpo, ou seja, que tenham a capacidade de proporcionar aumento de volume e/ou de massa dos alimentos, substituindo o volume e a textura perdidos pela retirada do açúcar (14, 40). Entre os agentes de corpo, os polióis são compostos com características adoçantes, empregados na indústria alimentícia na formulação de diversos produtos sem açúcar, os quais não são cariogênicos e podem ser ingeridos por diabéticos. Estes compostos apresentam valor calórico semelhante ao da sacarose, motivo pelo qual não há redução do valor calórico do alimento. Em geral, podem provocar ação laxativa e diurética quando consumidos em excesso. Como exemplo de polióis tem-se o xilitol (doçura semelhante à da sacarose, convencionada como 1,0), o sorbitol (doçura relativa de 0,6 ), o manitol $(0,5)$ e o maltitol $(0,85)$, que podem ser combinados entre si ou empregados juntamente com edulcorantes intensos. Atuam como emulsificantes, estabilizantes, umectantes, crioprotetores e redutores do ponto de congelamento (31).

Um dos mais importantes pré-requisitos na utilização dos edulcorantes é a estabilidade a temperatura em que ocorre o processamento. Os açúcares e polióis são estáveis, sendo que os primeiros provocam a reação de Maillard (escurecimento). Dos edulcorantes intensos, apenas o aspartame não resiste a temperaturas elevadas, ocasionando perda do poder adoçante.

Nenhum edulcorante é adequado para todas as aplicações, contudo suas limitações podem ser minimizadas mediante combinações entre eles. A combinação tem por objetivo aumentar o poder adoçante aproveitando o efeito de sinergismo que permite redução no nível de utilização dos edulcorantes e no custo do produto final. Além disso, a combinação visa 
mascarar sabores residuais e obter perfil de doçura mais próximo ao da sacarose. Outra vantagem é evitar a exposição do consumidor a um único adoçante fazendo com que a quantidade de cada edulcorante permaneça muito abaixo da sua ingestão diária aceitável (IDA) e de acordo com os limites legais. Um exemplo clássico é o sinergismo entre sacarina e ciclamato que são usados freqüentemente em combinação, para que a sacarina aumente o poder adoçante do ciclamato e este diminua o residual amargo da sacarina (13).

\section{SUBSTITUTOS DE GORDURA}

O consumo de alimentos com baixo teor de gordura tem tido aumento considerável, principalmente nos Estados Unidos e Europa (1, 12, 28, 41). De acordo com pesquisa de mercado realizada por BRUHN et al. (12), cerca de $62 \%$ dos consumidores norte-americanos entrevistados consideram que o conteúdo de gordura é a informação mais relevante na escolha do produto.

O consumo excessivo de óleos e gorduras tem sido freqüentemente associado à obesidade, aumento da taxa de colesterol no sangue, alguns tipos de câncer e distúrbios das coronárias (2, 21, 24, 29). As autoridades médicas recomendam que o consumo de gordura na dieta humana represente, no máximo, $30 \%$ do total de calorias consumidas, sendo que menos de $10 \%$ deve ser proveniente de gorduras saturadas $(2,21,24)$. No entanto, apesar destes inconvenientes, os óleos e gorduras são importantes componentes dos alimentos. Fornecem calorias, ácidos graxos essenciais e vitaminas lipossolúveis, além de serem responsáveis por grande número de propriedades funcionais e sensoriais importantes nos alimentos, como textura, maciez, cremosidade, lubrificação, palatabilidade, sabor e aroma (25).

Para diminuir a gordura e o valor calórico dos alimentos pode-se reduzir ou eliminar a gordura da formulação, aumentando outros componentes cujo metabolismo gere menor quantidade de calorias, como as proteínas, carboidratos, fibras e água (43). Pode também ser necessário utilizar os chamados substitutos de gordura, de forma a manter as qualidades associadas ao produto tradicional, sendo que o substituto ideal deve manter as propriedades funcionais das gorduras sem contribuir com calorias (6). Segundo McGLINCHEY (28) os substitutos de gordura em panificação devem desempenhar o mesmo papel da gordura, ou seja, favorecer a aeração, a lubrificação da massa durante a fase de mistura, melhorar a textura do produto final e aumentar o volume do pão. 
Os substitutos de gordura estão divididos em três categorias principais. Os ingredientes de base protéica, derivados de proteína do leite, soro de leite e ovos são digeridos pelo organismo. Os ingredientes da classe dos carboidratos podem ser amidos e maltodextrinas que são absorvidos pelo organismo, as fibras (celulose, hemicelulose, carboximetilcelulose) e hidrocolóides (pectina, gelatina, goma guar, xantana, carragena, etc.), que não são digeridos pelo trato gastrointestinal. Os substitutos de base lipídica podem ser parcialmente absorvidos, como a caprenina e o salatrim, ou não serem digeríveis, como o olestra $(1,21,24)$. A monocaprina e a tricaprina têm sido utilizadas como substitutos de gordura, pois os triglicerídios e ácidos graxos de cadeia média são absorvidos pelo organismo, mas são metabolizados mais como carboidratos do que como lipídios, gerando, aproximadamente, $6,9 \mathrm{kcal} / \mathrm{g}$. Entretanto, em ensaios de panificação, a tricaprina e particularmente a monocaprina interferiram na formação da massa do pão e inibiram a fermentação (36).

Os emulsificantes são geralmente compostos esterificados de ácidos graxos, já bastante conhecidos e utilizados. Podem exercer funçõeschave das gorduras, porém apresentam geralmente o mesmo valor calórico e, por isso, provocam alguma redução calórica apenas porque são usados em menor quantidade. Os mais comuns incluem: lecitina, mono e diglicerídios, ésteres de poliglicerol, polisorbatos e estearoil lactilato de sódio. São componentes úteis em sistemas que imitam gorduras, contudo, a quantidade permitida para uso é limitada e alguns podem deixar aroma estranho, quando em níveis mais elevados $(22,40)$.

A gordura pode também ser substituída por inúmeros produtos, como:

\section{- Substâncias microparticuladas}

Materiais constituídos de partículas de formato esférico e tamanho menor que $3 \mathrm{~mm}$ (não são percebidos pela língua como partículas), que podem inchar, simulando as características sensoriais das gorduras. Os microparticulados podem ser derivados de celulose, como a celulose microcristalina, ou derivados de proteínas, geralmente de leite ou ovos. Os primeiros têm a capacidade de formar gel que propicia sensação cremosa, semelhante a das emulsões de óleo em água (22). Os últimos são constituídos de partículas similares, em tamanho e formato, às da gordura emulsificada, podendo atuar em panificação como condicionador e amaciante da massa e ajudar na formação e firmeza da estrutura, além de melhorar a dispersão e a performance dos emulsificantes num sistema com pouca gordura $(9,13,35)$. 
Obtidos pelo tratamento térmico (pré-gelatinização), químico ou enzimático de amidos que sofrem modificações funcionais. Certos tipos de amido podem formar creme de consistência suave, capaz de substituir gordura com grande redução calórica (de 9 para $1 \mathrm{kcal} / \mathrm{g}$ ). As maltodextrinas apresentam como propriedades funcionais mais importantes a baixa higroscopicidade, sabor suave, doçura extremamente baixa, alta viscosidade e controle da cristalização $(25,28)$.

\section{- Hemiceluloses}

Quimicamente são constituídas por grupo heterogêneo de polissacarídios de origem vegetal que contêm vários açúcares na molécula, como as pentosanas, presentes nos cereais, que contêm xilose e arabinose. Outros exemplos são as fibras de beterraba, de soja e de amêndoas. Há um subgrupo dentro da categoria das hemiceluloses que são as beta-glucanas. Ocorrem em todos os cereais, porém em maior concentração (2-6\%) na cevada e aveia, sendo que a aveia tem sido pesquisada como fonte de fibras solúveis e também para produção de substitutos de gordura (22).

\section{- Hidrocolóides}

Por definição são compostos poliméricos que formam gel ou atuam como espessantes em sistemas aquosos, como as gomas. Podem também apresentar outras propriedades funcionais como emulsificante, estabilizante, encapsulante e espumante. Sendo polímeros de cadeia longa, com estrutura predominante de carboidratos, apresentam capacidade de se solubilizar ou inchar em sistemas aquosos, fornecendo características de viscosidade semelhante às gorduras. Fisiologicamente, os hidrocolóides funcionam como fibras solúveis e, portanto, não contribuem com calorias, ajudando a reduzir o colesterol do sangue e a moderar a resposta à glicose dos diabéticos (22).

Para proporcionar a sensação de corpo e a consistência suave e cremosa, associada às gorduras, pode-se usar agentes de corpo como os polióis (já mencionados) e a polidextrose. A polidextrose, embora possa também ser empregada como substituto de açúcares, não é doce. Substitui parcialmente as gorduras, atuando na estrutura, textura e conservação do produto. Além disso, apresenta baixo valor calórico, apenas $1 \mathrm{kcal} / \mathrm{g}$ $(3,14,22)$. 
Para alterar determinada formulação, primeiramente, é preciso identificar o papel da gordura naquele produto, de modo a poder escolher o(s) substituinte(s) mais adequado(s) (43). Dependendo do produto será necessário imitar uma ou mais características fornecidas pelas gorduras, por isso pode-se utilizar desde componentes simples até sistemas complexos. Os compostos descritos são normalmente utilizados em conjunto, combinando componentes com efeito sinérgico para obter substitutos de gordura mais eficazes. De acordo com estudioso do assunto (22), o sistema ideal consiste em um agente espessante, um agente de corpo e compostos microparticulados (Quadro 1). Os componentes do sistema devem simular as propriedades da gordura como lubrificação, aumento da consistência, textura de gel, opacidade, atividade de água reduzida e liberação de aromas (43). Usando-se, seletivamente, ingredientes destas três categorias é possível formular produtos variados, de boa qualidade, com baixo teor ou nenhuma gordura.

\section{QUADRO 1 - COMPONENTES DE SISTEMA PARA SUBSTITUIÇÃO DE GORDURAS}

\begin{tabular}{|c|c|c|c|}
\hline COMPONENTES & ESPESSANTES & AGENTES DE CORPO & MICROPARTICULADOS \\
\hline Objetivo & $\begin{array}{c}\text { Proporcionam } \\
\text { lubrifica }{ }^{a} 0 \\
\text { (controle de fluxo) }\end{array}$ & Controlam absor $\stackrel{a}{0} 0$ & $\begin{array}{l}\text { Agem como rolamentos de } \\
\text { esferas (fluxo livre) }\end{array}$ \\
\hline Solubilidade & $\begin{array}{l}\text { Soloreis e com } \\
\text { capacidade de } \\
\text { inchamento }\end{array}$ & Soloeis & Insolœeis \\
\hline Exemplos & $\begin{array}{l}\text { Gomas, amidos e } \\
\text { hemiceluloses }\end{array}$ & $\begin{array}{c}\text { Polidextrose, poli is, } \\
\text { hidrocol ides de } \\
\text { baixa viscosidade, } \\
\beta \text {-glucanas }\end{array}$ & $\begin{array}{l}\text { Celulose microcristalina, } \\
\text { prote na microparticulada }\end{array}$ \\
\hline
\end{tabular}

É mais facilmente obtida a redução calórica em bolos do que em pães, pois nos bolos a quantidade de gordura e açúcar é maior. Porém, a diminuição ou retirada de componentes pode afetar a estabilidade 
microbiológica do produto devendo ser usados ingredientes capazes de imobilizar a água (hidrocolóides, agentes de corpo). No caso dos pães, o problema não se restringe às quantidades de açúcar e gordura, sendo necessário diminuir também a quantidade de farinha de trigo, que é o ingrediente majoritário e excelente fonte de amido e proteína. Ambos os componentes apresentam o mesmo valor calórico, porém a proteína (glúten) desempenha função estrutural indispensável neste produto, não podendo sofrer redução acentuada. O amido é mais facilmente substituível por ingredientes menos calóricos, como fibras, amidos modificados, maltodextrinas, polidextrose, hemiceluloses e gomas.

\section{FIBRA DE ORIGEM VEGETAL}

A fibra alimentar foi definida como polissacarídios e lignina da célula vegetal que não são hidrolisados pelas enzimas digestivas de seres humanos e animais $(23,27,39)$. De acordo com GORDON (23) esta definição pode ser inadequada, porque elimina outros importantes polímeros, tais como os produtos da reação de Maillard, amidos resistentes à digestão e polidextroses. Este autor divide a fibra alimentar em solúvel e insolúvel sugerindo o uso do termo "fibra alimentar total", o qual inclui todos os polímeros presentes em alimentos que não sejam metabolizados pelas enzimas no intestino delgado.

Existem duas classes de polissacarídios: o amido e os polissacarídios não-amiláceos (NSP). O amido é hidrolisado a oligossacarídios pela alfaamilase, o que não ocorre com os NSP. Os polissacarídios não-amiláceos (compostos de celulose e hemicelulose) formam a parede celular e, juntamente com a lignina, são geralmente considerados como fibras (19). Devido à diversidade química e física dos NSP, a metodologia para sua determinação tem sofrido constante modificação $(19,30,33)$.

Vários pesquisadores $(23,27,39)$ têm relatado a incidência crescente de determinadas doenças, principalmente em países desenvolvidos, como câncer de cólon, arteriosclerose, apendicite e hemorróidas, relacionandoas com o baixo consumo de fibras. O mecanismo pelo qual a fibra exerce redução dos níveis de colesterol no sangue está relacionado com os ácidos biliares. Pessoas que consomem muita fibra excretam mais ácidos biliares, esteróis e gordura, que são seqüestrados pela fibra, prevenindo a reabsorção $(27,39)$.

Segundo POTTER et al. (32) o consumo de proteína e fibra de soja, 
utilizadas em pães, "muffins", biscoitos e bolos, associado a outros produtos de baixas calorias foi efetivo na redução do colesterol total da "low density lipoprotein" (LDL), conhecida como "mau colesterol", enquanto que o nível de "high-density lipoprotein" (HDL) foi mantido no sangue.

A fibra, apesar de apresentar várias vantagens para a nutrição humana, pode também gerar resultados negativos, quando consumida em excesso. De acordo com LARSSON \& SANDBERG (26) nas fibras obtidas, principalmente, de cereais, legumes e algumas frutas, a presença de fitato causa efeito negativo sobre a absorção de alguns minerais como zinco, ferro, magnésio e cálcio, pois propicia a formação de complexos insolúveis. Estes mesmos pesquisadores observaram que durante 0 processo de fermentação, ocorrido na fabricação de pães enriquecidos com farelo de aveia e de centeio, houve considerável redução nos teores de fitato, principalmente em função do efeito do baixo $\mathrm{pH}$ no aumento da atividade de fitase (26).

As principais fontes de fibra disponíveis no mercado são aquelas oriundas do processamento industrial de cereais, leguminosas e outros tipos de vegetais. De acordo com RAO \& RAO (34) somam-se a estas fontes de fibras outros compostos, como a goma guar e a alfa-celulose. O conteúdo de fibra alimentar no farelo sofre influência do grau de moagem e do teor de amido (38).

As dificuldades na formulação de produtos com alta concentração de fibras se deve a pobre funcionalidade da fibra e seus efeitos prejudiciais sobre as propriedades funcionais de outros componentes do alimento (4). Portanto, torna-se evidente a necessidade de adequar alto nível de fibra no alimento com pequena mudança em suas características sensoriais e de textura, tornando o produto aceitável pelo consumidor.

De acordo com STAUFFER (42) existem duas razões para se adicionar fibra em pães, sendo a primeira o aumento do teor de fibra alimentar consumida e a segunda, o decréscimo do conteúdo calórico destes pães.

\section{AMIDO RESISTENTE}

O termo "amido resistente" é empregado para definir o amido que não é digerido pelo trato intestinal do homem sadio. $\mathrm{O}$ amido pode resistir à digestão no intestino delgado por três razões principais, ou seja, pelo aprisionamento físico dentro de outro alimento (amido resistente do tipo 
1), pela estrutura dos grânulos de amido (tipo 2) ou por retrogradação durante o processamento (tipo 3) $(16,17,18)$. Em função destas observações, ENGLYST et al. (20) propuseram a classificação nutricional de amido como rapidamente digerível, lentamente digerível e amido resistente. $\mathrm{O}$ amido resistente é parcialmente metabolizado (cerca de $2,8 \mathrm{kcal} / \mathrm{g}$ ) e pode ser utilizado como fonte de fibra dietética na produção de alimentos (13). Vários autores consideram que, analiticamente, o amido resistente deveria ser incluído nos resultados de fibra alimentar, pois suas propriedades fisiológicas são similares às de certos polissacarídios fibrosos. Entretanto, a quantidade deste amido não-digerido dependeria não somente de suas características particulares (tais como a proporção entre amilose e amilopectina, cristalinidade, temperatura de gelatinização), mas também do tratamento da amostra a ser analisada, como moagem ou cozimento. Assim, a quantidade de amido resistente incluída no resultado de fibra alimentar poderia não refletir a quantidade real de amido resistente na digestão humana (37).

Em recente revisão sobre o papel do amido resistente na nutrição humana, realizada por BJÖRCK \& ASP (8), foram destacados alguns efeitos vantajosos do consumo deste tipo de amido. Como exemplo citaram a redução do pH no intestino delgado, formação de ácidos graxos de cadeia curta, aumento do volume das fezes, proteção contra o câncer de cólon, aumento da tolerância à glicose e redução dos níveis de lipídios. A maioria destes efeitos é observado também para a fibra vegetal.

Quanto às características tecnológicas, o amido resistente apresenta como principais vantagens sobre os demais tipos de fibra a cor branca e ausência de aroma, além de partículas de menor tamanho que tendem a melhorar a textura dos produtos nos quais é utilizado (15).

\section{CONCLUSÃO}

Para a obtenção de produtos de panificação com conteúdo calórico reduzido é preciso adaptar a formulação dos mesmos, substituindo alguns dos itens convencionalmente usados por outros ingredientes que exerçam funções tecnológicas semelhantes, porém que contribuam com menor aporte calórico ao produto. Esta revisão descreve uma série de ingredientes que podem ser usados com essa finalidade, os quais devem ser combinados de modo a resultar em produtos de panificação com características semelhantes aos convencionais. 


\begin{abstract}
BREADMAKING PRODUCTS WITH REDUCED CALORIC CONTENT

This article is a literature review about the ingredient types developed and/or recommended for the formulation of breadmaking products with reduced caloric content. Several possibilities were identified in reducing caloric content of breadmaking products, which ingredients must be tested and combined, aiming the obtention of products that should comply with consumer demands and legal requirements.
\end{abstract}

KEY-WORDS: BREADMAKING; FAT REPLACERS; SWEETENERS; LIGHT PRODUCTS.

\title{
REFERÊNCIAS
}

$1 \mathrm{AKOH}, \mathrm{C.C.}$ Fat replacers: present and future. In: LATIN AMERICAN CONGRESS AND EXHIBIT ON FATS AND OILS PROCESSING, 6. 1995, Campinas. Proceedings... Campinas: UNICAMP, 1995. p. 83-94.

2 ALEXANDER, R.J. Fat replacers based on starch. Cereal Foods World, St. Paul, v. 40, n. 5, p. 366-368, 1995.

3 APPL, R. C. Confectionery ingredients from starch. Food Technology, Chicago, v. 45, n. 3, p. 148-149, 1991.

4 ARTZ, W.E.; WARREN, C.C.; MOHRING, A.E.; VILLOTA, R. Incorporation of corn fiber into sugar snap cookies. Cereal Chemistry, St. Paul, v. 67, n. 3, p. 303-305, 1990.

5 BARNDT, R. L.; JACKSON, G. Stability of sucralose in baked foods. Food Technology, Chicago, v. 44, n. 1, p. 62-66, 1990.

6 BATH, D. E.; SHELKE, K.; HOSENEY, R. C. Fat replacers in highratio layer cakes. Cereal Foods World, St. Paul, v. 37, n.7, p. 495500, 1992.

7 BELL, J. High intensity sweeteners: a regulatory update. Food Technology, Chicago, v. 47, n. 11, p. 136, 1993.

8 BJÖRCK, I.; ASP, N.-G. Controlling the nutritional properties of starch in foods: a challenge to the food industry. Trends in Food Science \& Technology, Cambridge, v. 4, n. 7, p. 213-218, 1994. 
9 BLENDS reduce fat in bakery products. Food Technology, Chicago, v. 48, n. 6 , p. 168-170, 1994.

10 BRASIL. Ministério da Saúde. Secretaria de Vigilância Sanitária. Portaria n. 27, 13 jan. 1998. Aprova regulamentação técnica sobre informação nutricional complementar. Diário Oficial [da] República Federativa do Brasil, 16 jan. 1998. Seção 1.

11 BRASIL. Ministério da Saúde. Secretaria de Vigilância Sanitária. Portaria n. 29, 13 jan. 1998. Aprova regulamentação técnica sobre alimentos para fins especiais. Diário Oficial [da] República Federativa do Brasil, 15 jan. 1998. Seção 1. (Republicada em 30/ 03/98).

12 BRUHN, C.; COTTER, A.; DIAZ-KNAUF, K.; SUTHERLIN, J.; WEST, E.; WIGHTMAN, N. WILLIAMSON, E.; YAFEE, M. Consumer attitudes and market potential for dairy products utilizing fat substitutes. Journal Dairy Science, v. 75, p. 2569-2577, 1992.

13 CÂNDIDO, L. M. B.; CAMPOS, A. M. Alimentos para fins especiais: dietéticos. São Paulo: Varela, 1996.

14 COUNTING the calories. Food Manufacture, London, v. 68, n. 5, p. 24-25, 1993.

15 CROGHAN, M. Novelose, resistant starch: a novelty in the functional fibre sector. Alimentaria, Madrid, v. 261, p. 37-41, 1995.

16 CUMMINGS, J.H.; BEATTY, E.R.; KINGMAN, S.M.; BINGHAM, S.A.; ENGLYST, H.N. Digestion and physiological properties of resistent starch in the human large bowel. British Journal of Nutrition, Cambridge, v. 75, p. 733-747, 1996.

17 EERLINGEN, R.C.; CILLEN, G.; DELCOUR, J.A. Enzyme-resistant starch. IV. Effect of endogenous lipids and added sodium dodecyl sulfate on formation of resistant starch. Cereal Chemistry, St. Paul, v. 71, n. 2, p. 170-177, 1994.

18 EERLINGEN, R.C.; CROBEZ, M.; DELCOUR, J.A. Enzyme-resistant starch. I. Quantitative and qualitative influence of incubation time and temperature of autoclaved starch on resistant starch formation. Cereal Chemistry, St. Paul , v. 70, n. 3, p. 339-344, 1993.

19 ENGLYST, H.N.; ANDERSON, V.; CUMMINGS, J.H. Starch and non-starch polysaccharides in some cereal foods. Journal of the 
Science of Food Agriculture, London, v. 34, p. 1434-1440, 1983.

20 ENGLYST, H. N.; KINGMAN, S. M.; CUMMINGS, J. H. Classification and measurement of nutritionally important starch fractions. European Journal of Clinical Nutrition, v. 46, suppl. 2, p. S33S50, 1992.

21 GIESE, J. Fats, oils and fat replacers. Food Technology, Chicago, v. 50, n. 4, p. 78-84, 1996.

22 GLICKSMAN, M. Hydrocolloids and the search for the "Oily Grail". Food Technology, Chicago, v. 45, n. 10, p. 94, 96-101, 103, 1991.

23 GORDON, D.T. Functional properties vs physiological action of total dietary fiber. Cereal Foods World, St. Paul, v. 34, n. 7,p. 517-525, 1989.

24 GROSSKLAUS, R. Fat replacers: requirements from a nutritional physiological point of view. Fett/Lipid, Weinheim, v. 98, n. 4, p. 136$141,1996$.

25 HEWITT, L. The low fat no fat boom. Food Manufacture, London, v. 68, n. 3, p. 23-24, 1993.

26 LARSSON, M.; SANDBERG, A.-S. Phytate reduction in bread containing oat flour, oat bran or rye bran. Journal of Cereal Science, London, v. 14, p. 141-149, 1991.

27 LEVEILLE, G.A. Dietary fiber. Cereal Foods World, St. Paul, v. 21, n. 6, p. 255-258, 1976.

28 McGLINCHEY, N. Los almidones especiales abren nuevas oportunidades a la hora de sustituir las grasas empleadas en bollería. Alimentaria, Madrid, v. 276, p. 109-114, 1996.

29 MENSINK, R.P. Effects of fats and oils on risk factors for coronary heart disease. In: LATIN AMERICAN CONGRESS AND EXHIBIT ON FATS AND OILS PROCESSING, 6., 1995, Campinas. Proceedings... Campinas: UNICAMP, 1995, p.95-97.

30 MONGEAU, R.; BRASSARD, R. Enzymatic-gravimetric determination in foods of dietary fiber as sum of insoluble and soluble fiber fractions: summary of collaborative study. Journal of AOAC International, Arlington, v. 76, n. 4, p. 923-925, 1993. 
31 OLINGER, P. M. ; VELASCO, V.S. Opportunities and advantages of sugar replacement. Cereal Foods World, St. Paul , v. 41, n. 3, p. 110-117, 1996.

32 POTTER, S.M.; BAKHIT,R.M.; ESSEX-SORLIE,D.L.; WEINGARTNER, K.E.; CHAPMAN, K.M.; NELSON, R.A.; PRABHUDESAI, M.; SAVAGE, W.D.; NELSON, A.I.; WINTER, L.W.; ERDMAN, J.W. JR Depression of plasma cholesterol in men by consumption of baked products containing soy protein. American Journal of Clinical Nutrition, v. 58, n. 4, p. 501-506, 1993.

33 PROSKY, L.; ASP, N.-G.; FURDA, I.; DeVRIES, J.W.; SCHWEIZER, T.F.; HARLAND, B.F.; RAO, H.P.; RAO, M.H. Effect of incorporating wheat bran on the rheological characteristics and bread making quality flour. Journal of Food Science and Technology, Mysore, v. 28, n. 2, p. 92-97, 1991.

34 RAO, P.H.; RAO, H.M. Effect of incorporation wheat bran on the rheological characteristics and bread making quality of flour. Journal of Food Science and Technology, Mysore, v. 28, n. 2, p. 92-97, 1991.

35 REDUCED-FAT bakery foods: meeting the taste challenge. Prepared Foods, Chicago, v. 162, n. 8, p. 79-80, 1993.

36 ROACH, R.R.; HOSENEY, R.C. Monocaprin and tricaprin in breadmaking. Cereal Chemistry, St. Paul , v. 73, n. 2, p. 197-198, 1996.

37 SAMBUCETTI, M.E.; ZULETA, A. Resistant starch in dietary fiber values measured by the AOAC method in different cereals. Cereal Chemistry, St. Paul , v. 73, n. 6, p. 759-761, 1996.

38 SAUNDERS, R.M. The properties of rice bran as a foodstuff. Cereal Food World, St. Paul , v. 35, n. 7, p. 632-636, 1990.

39 SCALA, J. Fiber: the forgotten nutrient. Food Technology, Chicago, v. 28, p. 34-36, 1974.

40 SHUKLA, T.P. Problems in fat-free and sugarless baking. Cereal Foods World, St. Paul , v. 40, n. 3, p. 159-160. 1995.

41 SPECTER, S.E.; SETSER, C.S. Sensory and physical properties of a reduced-calorie frozen dessert system made with milk fat and sucrose substitutes. Journal Dairy Science, v. 77, p. 708-717, 1994. 
42 STAUFFER, C.E. Fiber Sources. In: FUNCTIONAL additives for bakery foods. New York: AVI Books, 1990. p. 191-197.

43 WARD, F. M. Hydrocolloid systems as fat mimetics in bakery products: icings, glazes and fillings. Cereal Foods World, St. Paul, v. 42, n. 5, p. 386- 390, 1997. 